\title{
Memória no Santuário de Fátima: um estudo discursivo sobre a narrativa das aparições
}

\author{
Carolina de Moraes Souza \\ Mestra; Universidade de Coimbra; Coimbra, Portugal \\ cmoraesouza@gmail.com

\section{Francilaine Munhoz de Moraes} \\ Doutora; Universidade de Brasília; Brasília, DF, Brasil \\ moraesfranci@yahoo.com.br
}

\section{Resumo}

Neste artigo, investigamos o processo de rememoração no espaço de confluência entre os campos da História e do Jornalismo. A pesquisa se constrói com base em estudo conceitual sobre acontecimento e temporalidade, e metodologia de análise discursiva. O estudo de caso analisa reportagens publicadas pela revista Sábado sobre os bastidores da visita do papa Francisco ao Santuário de Fátima, em Portugal, em maio de 2017. Como resultados, a pesquisa revela: a paráfrase das aparições de Fátima entrelaça o passado ao futuro, por meio da narrativa do presente; a comemoração do centenário é o acontecimento-espetáculo, cuja temporalidade funde passado, presente e futuro e permite abrigar o símbolo dos fenômenos de Fátima; o espaço do Santuário, cidade onde se realiza a celebração, permite conservar o símbolo do acontecimento histórico - sacralização da repetição - e, como lócus de memória, o entrelaçar das temporalidades.

\section{Palavras-chave}

Memória. Acontecimento. Temporalidades. Discurso.

\section{Introdução}

Desde os primeiros estudos sobre a memória coletiva, ainda em 1925, Halbwachs (1990), destaca que “[...] a lembrança é em larga medida uma reconstrução do passado com a ajuda de dados emprestados do presente." (HALBWACHS, 1990, p. 71). A partir daí, iniciase uma problematização sobre a memória e as estruturas sociais nos campos da Psicologia, 
História e Comunicação. Nora (1993) e Huysen (2000) alegam que os anos 1980 inauguraram o processo de sedução memorial, no qual os lugares de memória compensam as perdas das tradições vividas e dos costumes transmitidos nas experiências da vida cotidiana.

O fascínio memorial é explicado por esses autores como o desejo incessante pela desaceleração perante um rápido empurro para o futuro global que não inspira confiança. É nesse contexto de valorização da memória em busca de conforto que se destaca a atuação da mídia no processo de rememoração na contemporaneidade. Neste trabalho, pretendemos investigar esse processo por meio das comemorações, que reverberam na mídia e são capazes de entretecer as temporalidades: passado, presente e futuro. 0 estudo do acontecimento oferece suporte para perceber os casos catalizadores da atenção da mídia, que atualiza o fato ocorrido no passado por meio da narrativa noticiosa (MEDINA, 2003; SOUZA, 2002).

Com base em estudo conceitual sobre acontecimento e temporalidade, este artigo busca, portanto, investigar o processo de rememoração no espaço de confluência entre a História e o Jornalismo. A pesquisa proposta tem como objetivo contribuir com o debate acadêmico em torno do paradigma da temporalidade entre a História e o Jornalismo, bem como as representações memoriais construídas a partir da narrativa jornalística.

Elegemos como estudo de caso reportagens publicadas na revista Sábado sobre os bastidores da visita do Papa ao Santuário de Fátima, em Portugal, em maio de 2017, para a comemoração do centenário das 'aparições' e a canonização dos 'pastorinhos'. A ampla cobertura midiática sobre os bastidores da visita do Papa a Fátima despertou nossa curiosidade acadêmica: como o processo de rememoração ocorre nesses eventos discursivos? Como compreendê-los na perspectiva histórica? Para responder a essas indagações de pesquisa, neste artigo construímos a fundamentação teórica ao discutir as relações conceituais seção 2), descrevemos os fenômenos singulares que originam os eventos (seção 3), os quais são analisados discursivamente (seção 4), para tecermos, por fim, nossas considerações sobre o tema (seção 5).

\section{Acontecimento e temporalidade}

A análise do acontecimento histórico, a partir de meados do século XX, tornou-se uma incursão no universo social de vestígios e mutações deixadas pela ocorrência do 
próprio acontecimento (DOSSE, 2013). 0 autor observa o acontecimento como um enigma que instiga as capacidades de racionalidade e saturação de sentido e que perduram até mesmo após a sua ocorrência. Assim, o acontecimento se metaforiza como fênix, que ressurge diversas vezes provocando configurações sempre inéditas, nas quais sugerem renovado interesse pelos fenômenos singulares.

A reavaliação do acontecimento, ou o seu renascer, ocorre no período em que, não só a História, mas as diversas ciências humanas, como o Jornalismo e as Ciências Sociais, retomam a discussão para além do mero acontecimento e transpõem suas reverberações na sociedade contemporânea marcada pela instantaneidade. Visto como indício ou vestígio significante para a história, o acontecimento passa a ser considerado com caráter duplo, confirmando uma forma de irrupção do novo e uma ideia inesperada de ruptura no percurso do tempo.

Babo-Lança (2011) propôs o acontecimento como ruptura e descontinuidade temporal em relação à experiência humana. A descontinuidade, para a autora, presume a situação de um observador no tempo e uma visão sobre o acontecimento, ou seja, o acontecimento afeta alguém ou uma comunidade por sua capacidade de surpreender, perturbar e gerar consequências. Por conseguinte, o significado do acontecimento está diretamente ligado a uma ordem simbólica e convencional em que todo acontecimento é interpretado e percebido dentro de um horizonte de historicidade.

Mead (2008), ainda em 1932, considerou que o acontecimento é "aquilo que viria a ser" (MEAD, 2008, p. 55) ou seja, os acontecimentos estão em uma espessura temporal e espacial, que permitem sua ocorrência indo de um passado a um futuro. Nessa perspectiva, o acontecimento foge da visão determinista da duração imediata e efêmera. 0 mundo, segundo o argumento de Mead, é constituído de processos, emergências, evoluções e transições e é essa realidade que permite o surgimento de algo novo e também produz os acontecimentos. Por sua vez, o acontecimento também condiciona aquilo que "vem a ser", tomando o lugar de um trajeto contínuo de mudança, que está em curso no presente e é capaz de alcançar o futuro.

Ao considerar o acontecimento algo que está em curso no presente e que perdura, Mead (2008) afirma a condição de um presente diferenciado, ou como denomina o autor specious present. Tal conceituação reitera a visão de que o acontecimento está além da experiência instantânea, assim, o que o diferencia é exatamente o "além instante" que modifica sua natureza. Mead (2008) também salienta que a espessura temporal do 
acontecimento demonstra não só sua ocorrência em um presente que se estende ao futuro, mas também apresenta sua relação com o passado. Por isso, avalia que a produção do acontecimento revela suas condições precedentes e referencia o passado para gerar inteligibilidade.

Assim, o acontecimento "[...] cria, com seu caráter único, um passado e um futuro Desde que o vemos, ele se torna uma história e uma profecia [...]" (MEAD, 2008, p. 52). Para Mead (2008), as relações do acontecimento com as condições de seu passado produzem uma história, que a torna relativa ao próprio acontecimento. 0 acontecimento, portanto, se desenrola segundo a própria dinâmica, assumindo ritmos temporais variáveis, nos quais se intercalam passado, presente e futuro.

Ao assumir a variação de ritmos temporais do acontecimento, Mead (2008) aproxima sua análise àquela realizada por Koselleck (2014) sobre o tempo na História. Koselleck (2014)considera que os "estratos do tempo" remetem a diferentes planos, com distintas durações e origens, passíveis de atuar e estar presentes simultaneamente. Os estratos refletem a metáfora utilizada para designar a representação do tempo por meio de movimentos em unidades espaciais. Nas palavras do autor, " [...] muitas coisas acontecem ao mesmo tempo, emergindo, em diacronia ou sincronia, de contextos completamente heterogêneos" (KOSELLECK, 2014, p. 9).

A percepção do tempo estratificado de Koselleck (2014) reforça a condição de temporalidade espessa do acontecimento, usada neste trabalho. Em obra complementar, Koselleck (2006) avalia que experiência e expectativa são duas categorias adequadas para tratar do tempo histórico, pois ambas são capazes de entrelaçar o passado ao futuro. É no espaço de experiência que os acontecimentos podem ser incorporados e lembrados, enquanto que o horizonte de expectativa está voltado para o futuro próximo, para o não experimentado. A experiência pertence ao passado que se concretiza no presente, por meio da memória, dos vestígios, das permanências e das fontes. Portanto, a experiência funciona como um passado atual, no qual os acontecimentos foram incorporados e onde eles podem ser lembrados. Já a expectativa é tudo aquilo que hoje visa o futuro, se realiza no presente, mas se constitui no futuro próximo. Dessa forma, o autor utiliza os termos espaço de experiência e horizonte de expectativa para formalizar um conceito do tempo histórico. 0 que se estuda nesse artigo é o acontecimento como elemento da tensão entre o espaço de experiência e horizonte de expectativa. 
Para Farge (2002), a espessura temporal é inerente ao acontecimento. Ela é capaz de unir espaço de experiência, passado e perspectiva de espera. Dessa maneira, segundo a autora, o acontecimento antecipa e relembra e isso é intrínseco a sua existência. Ele é fabricado, deslocado e realizado no campo das emoções. Os atores históricos se tornam, assim, os responsáveis pela elaboração de emoções no acontecimento por meio dos modos de percepção e apropriação do que ocorreu.

A temporalidade do acontecimento se apresenta capaz, portanto, de entrelaçar uma rememoração do passado e uma expectativa do futuro, com a narrativa no e sobre o presente. Como explica Ricoeur (1985), tal relação entre temporalidades incentiva a produção de um jogo complexo de intersignificações, nas quais nossas expectativas estão dirigidas para o futuro e nossas interpretações são orientadas pelo passado. É dessa forma que o processo de rememoração é compreendido neste artigo.

Nesse sentido, como observa Babo-Lança (2011), existe uma dimensão pragmática no processo de rememoração do acontecimento, no qual se percebe uma reatualização, que lhe permite conferir a (re)participação no presente. Assim, a narrativa no presente ressignifica o acontecimento e lhe confere inteligibilidade em função dos seus efeitos conhecidos. Por isso, a autora considera que o ofício das mídias, que noticiam os acontecimentos, deve ser percebido como uma prática de memória, um exercício de rememoração, uma tarefa de evocação.

Nora (1993) vai além e considera a mídia um lugar de memória. Como salienta Nora (1993), os locais de memória geram curiosidade pelo momento de articulação da ruptura com o passado no qual se confundem com o sentimento de memória esfacelada. Assim, os lugares de rememorar nascem e sobrevivem apenas pelo sentimento atual de não haver memória espontânea e se desenvolvem com a necessidade de criar arquivos, livros, museus e outras simbologias não naturais de lembrança. Daí o porquê a obsessão pelo arquivo marcar a contemporaneidade. Para Nora (1993), essa característica afeta a preservação integral do presente e do passado, ou seja, "0 tempo dos lugares [de memória] é o momento [...] no qual desaparece um imenso capital em que se vivia na intimidade da memória e passa a se viver sob o olhar de uma história reconstituída." (NORA, 1993, p. 12).

No contexto midiático, uma das formas de reconstituir a história e colocá-la novamente no presente é por meio das comemorações. Estas funcionam como uma espécie de marco que reatualizam o passado, construindo-o novamente como acontecimento jornalístico, porém moldado de uma forma diferente daquela em que se deu a sua efetiva 
ocorrência.

Nessa perspectiva, Barbosa (2004) coloca que, por meio da presentificação do passado, a retórica da narrativa jornalística difunde o acontecimento comemorativo como informação e também como espetáculo. Assim, a memória estrutura-se por meio da montagem de uma indústria da comemoração. Nesse processo, relacionam-se “[...] o presente e o passado, razão pela qual os meios de comunicação tornam-se verdadeiros guardiões das comemorações contemporâneas e construtores de uma dada materialização da memória" (BARBOSA, 2004, p. 11). Desse modo, a mídia é um espaço privilegiado para disseminar as comemorações, em que prevalecem as relações entre passado e presente na construção do acontecimento e sua valoração pública.

\section{Fenômenos singulares}

Nuclear nesta pesquisa é o processo de rememorar - trazer à memória; lembrar - os fenômenos de Fátima, isto é, as aparições ocorridas entre 1916 e 1917. A história foi contada oralmente por três crianças - Lucia dos Santos, 10 anos, e seus primos Francisco Marto, 9 anos, e Jacinta Marto, 7 anos - e escritas por Lucia, entre 1937 e 1941, em suas Memórias ${ }^{1}$.

Segundo o relato, na cova da Iria, que ficava na aldeia de Fátima, as três crianças, enquanto cuidavam dos rebanhos - por isso, a denominação de pastorinhos -, testemunharam a seguinte aparição:

Andava eu com os meus primos Francisco e Jacinta a cuidar do rebanho e subimos a encosta em procura dum abrigo [...]. Então, começamos a ver, a alguma distância, sobre as árvores que se estendiam em direção ao nascente uma luz mais branca que a neve, com a forma dum jovem transparente, mais brilhante que um cristal atravessado pelos raios do Sol. À medida que se aproximava, íamos lhe distinguindo as feições [...] Estávamos surpreendidos e meio absortos. Não dizíamos palavra. Ao chegar junto de nós, disse: - Não temais. Sou o Anjo da Paz. Orai comigo. E ajoelhando em terra, curvou a fronte até ao chão. Levados por um movimento sobrenatural, imitámo-lo e repetimos as palavras que lhe ouvimos pronunciar [...] E desapareceu. A atmosfera do sobrenatural que nos envolveu era tão intensa, que quase não nos dávamos conta da própria existência, por um grande espaço de tempo [...]. A presença de Deus sentiase tão intensa e tão íntima, que nem mesmo entre nós nos atrevíamos a

\footnotetext{
${ }^{1}$ Lucia dos Santos (1907-2005) relatou suas memórias oralmente e por meio de cartas e testemunhos. Entre 1935 e 1941 escreve Memórias I a IV, compiladas e editadas pelo Secretariado dos Pastorinhos. Memórias I (KONDOR, 2007).
} 
falar. No dia seguinte, sentíamos o espírito ainda envolvido por essa atmosfera que só muito lentamente foi desaparecendo. Nesta aparição, nenhum pensou em falar nem em recomendar o segredo. Ela de si o impôs. [...]. Fez-nos talvez também maior impressão, por ser a primeira assim manifesta. (MACHADO, 1996, p. 33, grifo nosso).

Este fenômeno, descrito como sobrenatural pela própria narradora, ficou conhecido como a primeira aparição do Anjo de Portugal. Antes das aparições de Nossa Senhora, as crianças tiveram três aparecimentos do Anjo. No mesmo local onde avistaram o anjo, no ano seguinte, as crianças disseram testemunhar, em 13 de maio, dois clarões, como se fossem relâmpagos e em seguida viram " [...] uma Senhora vestida de branco, mais brilhante que o sol espagindo luz mais clara e intensa que um copo de cristal cheio de água cristalina, atravessado pelos raios do sol mais ardente."(MACHADO, 1996, p. 37). Segundo Lucia, ocorreu o seguinte diálogo:

NS: "Não tenhais medo, Eu não vos faço mal".

Lucia: "Donde é vossemecê?".

NS: "Sou do céu" (e Nossa Senhora ergue a mão para apontar o céu).

Lucia: "E que é que Vossemecê me quer?"

NS: "Vim para vos pedir que venhais aqui seis meses seguidos, no dia 13, a esta mesma hora. Depois vos direi quem sou e o que quero. Depois voltarei aqui uma sétima vez" (MACHADO, 1996, p. 39)

De acordo com a narrativa, naqueles encontros em 1917, Nossa Senhora contou três segredos às crianças, ou um segredo em que constam três revelações distintas: a primeira é a visão de um mar de fogo, que seria o inferno, segundo descreve Lúcia; a segunda faz referência à Rússia e pode ser interpretada como a premonição da queda do muro de Berlim em 1989; e a terceira, revelação que pode estar associada ao atentado contra o papa João Paulo II, ocorrido em 13 de maio de 19812. Ao todo, essas visões representam a mensagem de Nossa Senhora de Fátima, na interpretação do papa Bento XVI. Esta mensagem traduz-se hoje, segundo a reitoria do Santuário, na ideia da conversão do indivíduo, da peregrinação como uma experiência mística e individual em busca de Deus e do sagrado³.

Em torno do local onde se deram as aparições, foi erguido um Santuário. Os irmãos Francisco e Jacinta, que morreram de gripe espanhola em 1919 e 1920, respectivamente, estão enterrados na Basílica deste Santuário. A eles foram atribuídos dois milagres

\footnotetext{
2 Interpretações e comentários teológicos sobre os segredos de Fátima (visões ou premonições) podem ser consultados na página do Vaticano (VATICAN, 2017).

3 Disponível na página do Santuário de Fátima (2017).
} 
reconhecidos pela Igreja Católica, os quais possibilitaram a canonização, isto é, a transformação em santos. Lucia faleceu em 2005 e está em curso o processo de sua canonização.

Na mensagem de confirmação de sua vinda ao Santuário, o papa Francisco disse: "Vou levar pessoalmente a Portugal, se Deus quiser, estes votos de paz e esperança, na minha agora iminente peregrinação ao Santuário de Fátima, onde há cerca de 100 anos apareceu Nossa Senhora aos três Pastorinhos [...]" (SANTUÁRIO..., 2017, doc. não paginado). A visita do Papa ao Santuário de Fátima, em Portugal, nos dias 12 e 13 de maio de 2017, teve por objetivo, portanto, a participação na comemoração do centenário e, como parte desta, a canonização dos pastorinhos. Entendemos que a comemoração foi potencializada como evento midiático desde que houve a confirmação da presença do papa Francisco. Os bastidores desta visita são temas da análise e discussão que ora segue.

\section{Metodologia}

Nesta pesquisa, elegemos a análise discursiva pelo Caminho das Seis Leituras Interpretativas (PORTO, 2010, 2017), que se situa na abordagem da investigação hermenêutica. Nesse método analítico, as leituras são interdependentes e interpenetram-se dentre as quais escolhemos três leituras que se entrecruzam e são ferramentas adequadas aos objetivos da pesquisa.

A primeira delas, a Polissêmica ou Literária, desvela a multiplicidade de sentidos do texto. A segunda, a Parafrástica, busca a ideia dominante e central que se repete por meio de argumentos, ênfase e figuras de linguagem; e os sentidos estratificados, que se mantêm e se repetem. A terceira leitura, a Arqueológica, investiga as referências históricas e documentais do evento discursivo, lida com os arquétipos, a simbologia, os acervos das histórias das ideias.

A fim de selecionar os eventos discursivos para o exercício de interpretação, rastreamos as publicações sobre a iminente comemoração do centenário de Fátima e a visita do Papa. Elegemos, como estudo de caso, a revista Sábado (número 676, de 12 a 19 de abril de 2017), por seu especial sobre o tema, cujo título da reportagem de capa traz Os segredos da visita do Papa a Fátima... e todas as teorias da conspiração e subtítulo $A$ um mês da viagem de Francisco, saiba como foi preparada a viagem desde o primeiro momento - as reuniões e os encontros de quem ninguém soube e as combinações de bastidores. 
Integram o corpus dessa análise as matérias: (1) Os bastidores da visita do Papa, que trata da preparação para a chegada do Papa ao Santuário de Fátima, também mostra os números do planejamento para as comemorações do centenário e santificação dos pastorinhos (ANDRE, 2017a); (2) Ainda em vida os pastorinhos eram considerados santos, corresponde a uma entrevista com a postuladora da causa dos pastorinhos, Ângela Coelho, que conta sobre o processo de santificação dos irmãos (ANDRE, 2017b); (3) As treze virgens que viajam pelo mundo, que relata as viagens das esculturas itinerantes de Nossa Senhora de Fátima, são treze as imagens peregrinas (ANDRE, 2017c); e por último, (4) Aconteceu tudo menos a Virgem Maria, que narra sobre as teorias da conspiração que rodeiam a história das aparições de Nossa Senhora (ARSÉNIO; ESTEVES, 2017)4.

\section{Análise e discussão}

Esta seção dedica-se a análise das narrativas do corpus. Para isso, cada matéria é observada analiticamente como evento discursivo, mas também as quatro narrativas são examinadas como partes de um mesmo discurso, um todo que produz sentidos. À luz do viés hermenêutico do método adotado neste artigo e movidos pela atitude interpretativa, que busca o sentido das coisas, perscrutamos o vocabulário, as figuras de linguagem, as estratégias discursivas e o princípio de organização discursiva no corpus eleito.

\subsection{Unidade discursiva: presente, passado e futuro}

No caminho hermenêutico, iniciamos pela leitura parafrástica, que nos permite perceber a unidade discursiva. 0 termo "aparições" - e seu cognato "aparição" - é a paráfrase por excelência, que perpassa todos os eventos os discursivos (matérias 1, 2, 3 e 4), mantendo a unidade e a organização discursivas. É a ideia central que se mantém e se repete, retomando o sentido original e histórico do fenômeno de Fátima. Traz o passado, testemunhado em 1917 (ver seção 3), ao presente, em 2017, por meio da comemoração do centenário das aparições. Nesse aspecto, retomamos Babo-Lança (2011): “[...] o acontecimento é interpretado e [...] [percebido dentro de um] horizonte de historicidade." (BABO-LANÇA, 2011, p. 75).

\footnotetext{
${ }^{4}$ As matérias utilizadas na análise serão indicadas pelas numerações designadas a cada uma.
} 
A "saturação de sentido que perdura após a ocorrência." (DOSSE, 2013, P. 14) emerge na paráfrase das "aparições". Esta saturação, como explica o autor, ressurge em configurações inéditas - no caso em análise, a comemoração do centenário - de onde sugere renovado interesse pelos fenômenos singulares.

Ainda pela leitura parafrástica, os eventos discursivos sobre os bastidores da vinda do Papa e comemoração do centenário de Fátima compõem um mosaico a fim de criar um clima de expectativa e alimentar o imaginário sobre o futuro próximo. A escolha vocabular verbos receber, preparar e esperar - reforça e denota o aspecto de antevisão do acontecimento, observados, por exemplo, nas chamadas e legendas "Prontos para receber a multidão"; "O recinto prepara-se para receber o Sumo Pontífice a 12 e 13 de maio" (matéria 1, p. 37); “Espera-se mais de um milhão de pessoas em Fátima nas comemorações” (matéria 1, p. 36). Aqui vale o entendimento de Mead (2008) sobre o acontecimento como aquilo que viria a ser, algo que está em curso e que perdura, um presente diferenciado: specius present. Neste ponto, cumpre indagar como isso se consubstancia no campo do Jornalismo.

Como traço peculiar, que a distingue de outras modalidades, a narrativa jornalística compreende a arte de contar histórias da atualidade. Medina (2003) sintetiza: "O jornalismo faz da narrativa da atualidade sua matéria-prima [...]" (MEDINA, 2003, p. 92). No caso em análise, a mídia entrelaça o passado ao futuro, por meio da mediação do presente. Ao fazer a narrativa da atualidade, retoma o passado ("aparições") e evoca o futuro próximo (visita do Papa), movendo o leitor do presente narrado ao passado histórico e ao futuro imaginado. No jogo das temporalidades em que o acontecimento é apreendido neste trabalho, podemos perceber os eventos discursivos como espaços que entrelaçam o passado-presente-futuro. Apoia-nos nessa interpretação a percepção de temporalidade espessa do acontecimento de Koselleck (2006, 2014), em que os estratos do tempo, segundo o autor, são passíveis de atuar simultaneamente, emergindo em sincronia e diacronia.

\subsection{0 real e o sobrenatural no acontecimento-espetáculo}

A leitura parafrástica casada à leitura polissêmica dos eventos discursivos nos revela o jogo entre o real e o sobrenatural. A notícia - principal produto do processo de informação midiático - é concebida como “[...] artefato linguístico que procura representar determinados aspectos da realidade." (SOUZA, 2002, p. 13). A mídia confere notoriedade 
pública a determinadas ocorrências, ideias e temáticas, as quais representam discursivamente.

Desse modo, a narrativa noticiosa, pelas características de sua natureza discursiva, representa aspectos da realidade. No caso em análise, exerce essa característica ao refutar aquilo que considera alheio ao real, à realidade observável das coisas, como os fenômenos sobrenaturais de Fátima (ver seção 3). 0 título Aconteceu tudo menos a virgem Maria - As visões de uma mulher de branco terão sido uma fabricação política, obra de óvnis [...] (matéria 4, p. 44) questiona a veracidade dos fenômenos, instaura a dúvida e a polêmica. 0 evento discursivo traz sintagmas nominais como "teorias conspirativas", "fantasmas do inconsciente das crianças", "ilusão de óptica coletiva", os quais sugerem que há várias teorias e contestações sobre os fenômenos.

Foucault (1996) ensina que ninguém entrará na ordem do discurso se não satisfizer a certas exigências ou se não for, de início, qualificado para fazê-lo. Ora, o 'sobrenatural' não pertence à realidade, logo não está autorizado a entrar na narrativa noticiosa. Daí o questionamento, a contestação aos fenômenos sobrenaturais de Fátima nos eventos discursivos. Reforça essa apreensão o uso conjunto das seguintes figuras de retórica: ironia em aconteceu tudo menos a Virgem Maria e antítese tudo/nada 5 . Ao ironizar, a narrativa noticiosa traz para o campo do humor, do risível, aquilo que está fora da realidade observável, fora da ordem natural que ela representa discursivamente.

Por outro lado, a leitura polissêmica acerca do sobrenatural é carregada de significados não apreensíveis pelo real. Enquanto o real fecha, o sobrenatural abre as possibilidades significativas. Aqui entram os fenômenos não reconhecidos pela ciência, isto é, que não podem ser comprovados pelos princípios científicos, como, no caso em análise, as aparições marianas, os santos e os milagres (matéria 2, p. 44-46). Esses pertencem ao campo da fé e crença religiosas, e seu amplo espectro de sentidos.

A tensão entre real e sobrenatural nos eventos discursivos se neutraliza na figura da autoridade máxima da Igreja Católica, o papa Francisco. A visita do Papa é o acontecimento que legitima a cobertura midiática na comemoração do centenário de Fátima. Na narrativa jornalística, os objetivos da visita - lembrar os cem anos das aparições e canonizar, isto é, tornar santas as crianças que testemunharam os fenômenos, Jacinta e Francisco - são associados à crença católica e ao argumento de autoridade (matéria 2). No caso em análise, a

\footnotetext{
${ }^{5}$ Segundo Ducrot e Todorov (200) ironia e antítese são figuras de retórica. A ironia é o “[...] emprego de uma palavra com o sentido de seu antônimo" e a antítese é “[...] a aproximação de duas palavras antônimas, isto é, que comportam um sema oposto". (DUCROT; TODOROV, 2001, p. 254).
} 
construção do acontecimento e sua valoração pública ocorrem por meio do espetáculo da comemoração (BARBOSA, 2004).

Para dar suporte a esta apreensão, trazemos também o entendimento de Nora (1993). Nora (1993) considera que a mídia é responsável pela espetacularização dos acontecimentos ao salientar-lhes a grandeza. É o que percebemos na narrativa da reportagem Os bastidores da visita do papa (matéria 1). Nesta, o acontecimento é um espetáculo, mostrado em números grandiosos, como em "Prontos para receber a multidão": 100 ambulâncias na Cova da Iria, dois hospitais de campanha, 30 hospitais de prevenção; 43 postos da Cruz Vermelha; 500 operacionais da Protecção Civil, 150 novas metralhadoras, duas centenas de coletes, três helicópteros (matéria 1, p. 37). Para ratificar o acontecimentoespetáculo, os dados mostram uma cobertura midiática de equivalente magnitude, como observado em: "Será montada uma tenda extra para garantir que há espaço para todos os jornalistas. Será possível comunicar em sete línguas” (matéria 1, p. 36); “[...] ecrãs gigantes para que todos os peregrinos [...] possam acompanhar as celebrações" (matéria 1, p. 38).

Vale reforçar que, segundo Nora (1993), o acontecimento em forma de espetáculo se transforma em um símbolo eterno que consegue ultrapassar o instante da sua ocorrência, assumindo o caráter de instrumento da sacralização dos lugares, comportamentos, objetos e símbolos. Pelo acontecimento-espetáculo, portanto, passado, presente e futuro temporalidade espessa (ver seção 4.A) - fundem-se numa temporalidade que permite abrigar o símbolo eterno das aparições de Fátima.

\subsection{Arqueologia das aparições marianas e o santuário como lócus de memória}

No entrelaçamento entre as leituras arqueológica e parafrástica, percebemos que Nossa Senhora de Fátima apresenta diversas denominações, as quais adquirem inteligibilidade nos eventos discursivos por meio da cultura, memória e história vinculadas à sociedade cristã e ao culto mariano.

As diversas faces e fases da simbologia de Maria podem ser relacionadas ao uso de diferentes nomeações para a mesma figura nos eventos em análise. Nossa Senhora (matéria 2, p. 40), Virgem Peregrina (matéria 3, p. 42), Senhora Peregrina (matéria 3, p. 43), A Virgem (matéria 4, p. 44), Fátima (matéria 4, p. 44), Virgem Maria (matéria 4, p. 44) e Mulher de Branco (matéria 4, p. 44) são paráfrases para tratar do mesmo símbolo: a mãe de Jesus 
Cristo. Criado pela Igreja Católica na Idade Média, mas que demonstra vínculo com outras tantas simbologias femininas ao longo da história pagã, as diferentes faces de Maria e a arqueologia de sua representação foram essenciais para a construção de sentido do símbolo de fé.

Segundo Loyn (1990), foi no ano de 431, oficializado pelo Concílio de Éfeso, que a Igreja Primitivaformalizou o culto à Maria Santa. Durante a Idade Média, Maria foi venerada como a primeira entre todos os santos. Como explica Cunha (2011), o primeiro erudito a tratar sobre Maria, ainda na Antiguidade, foi São Justino (ano 165), que a denomina de Virgem e formula o binômio Eva-Maria, fazendo referência e em posição oposta à ação da primeira mulher pecadora da humanidade, segundo a Bíblia. Mais tarde, Santo Irineu (ano 178) a considera Mãe da Igreja e, para isso, utiliza a teoria da Nova-Eva. 0 culto à Maria tem início, pois, no Oriente e passa ao Ocidente no século V. A partir do século XI, conhece seu apogeu, como demonstra a maioria das catedrais consagradas à Nossa Senhora.

Para Boff (1979), Maria não é apenas a Mãe de Jesus e Mãe de Deus, mas também é a Mãe de todos os homens. É a Mãe espiritual dos pecadores arrependidos e intercessora dos homens no juízo final. Assim como ela gerou Jesus Cristo, ela continua a gerar os cristãos, tornando-se também a Mãe da Igreja Católica. Segundo Boff (1979), a fé dos cristãos em relação a Maria é constantemente construída no universo simbólico-mítico.

Na composição do símbolo de Maria, Boff (1979)considera ainda a influência das mitologias consideradas pagãs pelo cristianismo. Por isso, o autor revela que "[...] convertendo-se, os pagãos, veneradores de suas deusas e virgens, substituíram os nomes pagãos por aquele de Maria." (BOFF, 1979, p. 226). Entre as deusas mães tratadas como pagãs, situam-se: Ísis, a deusa do Nilo na mitologia egípcia; Inana e Istar, deusas do barro, nos mitos babilônicos; Géia, Deméter, Reía e Hera, as deusas do Olimpo grego; as diversas deusas do Ébano, reveladas em diferentes regiões africanas, nas quais cada uma delas possuía um símbolo materno e divino.

É esse sentido arqueológico que transpõe para Maria os títulos e a iconografia das deusas-mães e a transferência de antigos templos de divindades femininas. A essa construção de sentido agrega-se, também, a religiosidade popular, a qual foi conceituada por Lima (2001) como a forma de um povo expressar sua relação com o sagrado, por meio de símbolos, lugares, arquivos e comportamentos. Nesse âmbito, o símbolo de Maria associa-se à mãe-terra, à fecundidade que carrega a fé e a devoção. 
Os símbolos, arquivos e comportamentos podem ser observados nos eventos discursivos em análise. Os símbolos são representados pelas 13 virgens que viajam o mundo (matéria 3); o lugar de memória está associado ao local de peregrinação e fé, que é o Santuário de Fátima; e o comportamento que está ligado ao processo de peregrinação.

As virgens Marias viajantes como símbolo memorial apresentam um caráter universal e motivo da fé (matéria 3). A representação de Nossa Senhora é o símbolo mais forte dessa história a ser relembrada e, portanto, ela é a protagonista principal. Com base em Farge (2002), os atores históricos são responsáveis pela elaboração de emoções no acontecimento. É por isso que a imagem da virgem tem atuação principal no apelo emotivo do acontecimento, fazendo os fiéis atravessarem de um passado para um futuro com a representação desta personagem.

Além disso, a narrativa sobre a simbologia da Virgem Maria apresenta outra característica ligada à memória: a capacidade de ser reconhecida em diferentes lugares. Esse aspecto está relacionado aos estudos sobre a memória coletiva de Halbwachs (1990). Segundo Halbwachs (1990), para gerar inteligibilidade e sentido em uma memória é necessário que existam pontos de contato entre uma lembrança e outra, assim as recordações podem ser reconstruídas sobre um fundamento comum.

Pelo processo metonímico, ${ }^{6}$ as viagens das virgens Marias representam o peregrino: a imagem viaja do Santuário de Fátima para o mundo; as pessoas vêm de outros lugares do mundo para o Santuário. Assim, tanto as imagens peregrinas quanto os peregrinos se tornam difusores da memória de Maria.

Os santuários, sob os olhos do catolicismo e mais especificamente dos termos jurídicos-canônicos, “[...] entende-se a igreja ou outro lugar sagrado aonde os fiéis, por motivo de piedade, em grande número acorrem em peregrinação, com a aprovação do Ordinário do lugar." (VATICAN, 1983). No entanto, para a fé popular, o santuário se distingue de outros locus de devoção por sua associação ao grau mais elevado de sacralidade. Para Santos (2013), esses locais são a materialização visível do sagrado para os crentes e também são núcleos de transmissão de mensagens de conteúdo religioso, que potencializam a concretização de processos de difusão da fé e do culto. 0 santuário ainda é uma ferramenta da memória na qual evoca e reconstitui narrativas e imagens da relação do homem e sua coletividade com o sagrado.

\footnotetext{
${ }^{6}$ Segundo Ducrot e Todorov (2001), metonímia é “O emprego de uma palavra para designar um objeto ou uma propriedade que se encontram numa relação existencial com a referência habitual dessa palavra". (DUCROT; TODOROV, 2001, p. 254).
} 
Esse lugar de memória, como ensina Nora (1993), permite uma reavaliação do passado, por meio da construção do presente, processo em que se renova a fé do peregrino. Nesse sentido, o Santuário de Fátima pode ser considerado um museu, segundo as conceituações de Nora (1993) e Huysen (2000). Os museus foram criados para serem instituições pragmáticas responsáveis por colecionar, salvar e preservar o passado por meio de uma construção à luz do discurso presente e, portanto, num processo de reconstrução da história.

Local de renovação histórica, o Santuário é o espaço de contato com a história das aparições de Nossa Senhora, que transforma o cotidiano do homem, fazendo-o renunciar da rotina e assumir o sentido peregrino. Nesse movimento, ele aceita privar-se de sua situação em prol da exaltação do imaginário e da sociabilização da fé.

\section{Considerações finais}

Esta pesquisa focalizou o processo de rememoração - trazer à memória - no episódio da visita do papa Francisco para a comemoração do centenário das aparições no Santuário de Fátima em maio de 2017. Com base no suporte teórico e nas análises discursivas do corpus constituído por matérias acerca do episódio, percebemos que:

a) a paráfrase das aparições denota que narrativa jornalística entrelaça o passado ao futuro, por meio da mediação do presente. 0 acontecimento é apreendido no jogo das temporalidades;

b) a comemoração do centenário é o acontecimento-espetáculo, cuja temporalidade funde passado, presente e futuro - temporalidade espessa ou specius present KOSELLECK, 2006, 2014) - e permite abrigar o símbolo eterno das aparições ou fenômenos de Fátima. Ou, dito de outro modo, a construção do acontecimento e sua valoração pública ocorrem por meio do espetáculo da comemoração (BARBOSA, 2004);

c) um dos modos de 'espetacularizar' o acontecimento é salientar sua grandeza expressa em números (ver seção 4.B);

d) a narrativa noticiosa, pelas características de sua natureza discursiva, representa aspectos da realidade e refuta aquilo que considera alheio ao real, como os fenômenos sobrenaturais de Fátima. Nessa relação entre o real e o sobrenatural, 
a narrativa noticiosa, nos eventos discursivos, traz para o campo do risível (ironia) aquilo que está fora da realidade observável, que ela representa discursivamente;

e) o entrelaçamento entre a leitura arqueológica e parafrástica revela as diversas faces da simbologia de Maria. Esse sentido arqueológico transpõe para Maria os títulos e a iconografia das deusas-mães;

f) os símbolos, arquivos e comportamentos foram observados nos eventos discursivos: os símbolos são representados pelas 13 virgens que viajam o mundo; o lugar de memória está associado ao local de peregrinação e fé, o Santuário de Fátima; e o comportamento está ligado ao processo de peregrinação. A representação de Maria é o símbolo mais forte dessa história a ser relembrada;

g) o espaço do Santuário, onde se realiza o ritual de comemoração, permite conservar o símbolo do acontecimento histórico. Este se constrói na sacralização da repetição;

h) o Santuário de Fátima, como lócus de memória, expõe a dialética das temporalidades estudadas neste trabalho, servindo como câmara mortuária do passado e também como espaço de ressurgimento do acontecimento no futuro.

Por fim, entendemos que o processo comemorativo fornece à atualidade os sinais de um passado que rememora e também consolida a interpretação desses sinais por tradições sociais ainda pertencentes ao presente. A função da comemoração é, pois, representar e interpretar os vestígios, atualizando-os e institucionalizando, a partir deles, novas prospecções para o futuro.

\section{Referências}

ANDRE, Ana Catarina. Os bastidores da visita do Papa. Sábado, Lisboa, n. 679, p. 34-38, abr. 2017a. Matéria 1 nas análises.

ANDRE, Ana Catarina. Ainda em vida os pastorinhos eram considerados santos. Sábado, Lisboa, n. 679, p. 38-40, abr. 2017b. Matéria 2 nas análises.

ANDRE, Ana Catarina. As 13 virgens que viajam pelo mundo. Sábado, Lisboa, n. 679, p. 4142, abr. 2017c. Matéria 3 nas análises. 
ARSÉNIO, Dina; ESTEVES, Inês. Aconteceu tudo menos a virgem Maria. Sábado, Lisboa, n. 679, p. 44-46, abr. 2017. Matéria 4 nas análises.

BABO-LANÇA, Isabel. Configuração mediática dos acontecimentos do ano. Caleidoscópio, Lisboa, v. 1, n. 10, p. 73-84, 2011.

BARBOSA, Marialva. Jornalistas, senhores da memória? In: CONGRESSO DA INTERCOM, 27. 2004. Porto Alegre. Anais [...]. Porto Alegre: PUCRS, 2004. 1 CD-ROM.

BOFF, Leonardo. 0 rosto materno de Deus: ensaio interdisciplinar sobre o feminino e suas formas religiosas. Petrópolis: Vozes, 1979. v. 18.

CUNHA, Viviane. Os topos do jogral no acervo mariano medieval. Revista do Centro de Estudos Portugueses, Belo Horizonte, v. 31, n. 45, p. 167-187, jan./jun. 2011.

DOSSE, François. Renascimento do acontecimento. São Paulo: Unesp, 2013.

FARGE, Arlette. Pense et défini l'événement en histoire: approche des situations et des acteus sociaux. Revue d'ethnologie de l'Europe, Paris, n. 38, p. 67-78, mars 2002.

FOUCAULT, Michel. A ordem do discurso: aula inaugural no Collége de France, pronunciada em 1970. São Paulo: Loyola, 1996.

HALBWACHS, Maurice. A memória coletiva. São Paulo: Vértice, 1990.

HUYSEN, Andreas. Seduzidos pela memória: arquitetura, monumentos e mídia. Rio de Janeiro: Aeroplano, 2000.

KONDOR, Luís (org.). Memórias da Irmã Lúcia I. Secretariado dos Pastorinhos. Disponível em: <http://www.pastorinhos.com/_wp/wpcontent/uploads/MemoriasI_pt1.pdf>. Acesso em: 27 maio 2017.

KOSELLECK, Reinhart. Espaço de experiência e horizonte de expectativa. In: KOSELLECK, Reinhart. Futuro passado: contribuição à semântica dos tempos históricos. Rio de Janeiro: Contraponto, 2006. p. 305-327.

KOSELLECK, Reinhart. Estratos do tempo: estudos sobre a história. Rio de Janeiro: Contraponto, 2014.

LIMA, José. Religiosidade popular. In: AZEVEDO, Carlos. Dicionário de História Religiosa de Portugal. Lisboa: Círculo de leitores, 2001. v. 3, p. 107-120.

LOYN, Henry (org.). Dicionário da Idade Média. Rio de Janeiro: Jorge Zahar, 1990.

MACHADO, Antonio. As aparições e as mensagens de Fátima conforme os manuscritos da irmã Lucia. São Paulo: Artpress, 1996. 
MEAD, George. La filosofía del presente. Madrid: Centro de Investigações Sociológicas, 2008.

MEDINA, Cremilda. A arte de tecer o presente: narrativa e cotidiano. São Paulo: Summus, 2003.

NORA, Pierre. Entre memória e história: a problemática dos lugares. Projeto História, São Paulo, n. 10, p. 7-28, 1993.

PORTO, Sérgio. Análise de discurso: o caminho das seis leituras interpretativas em massa folhada. Brasília: Casa das Musas, 2010.

PORTO, Sérgio. As seis leituras interpretativas em massa folhada. In: PORTO, Sérgio; MOTA, Célia (org.). Hermenêutica e análise de discursos em jornalismo. Florianópolis: Insular, 2017. p. 95-112.

RICOEUR, Paul. Temps et récit III. In: RICOEUR, Paul. Le temps raconté. Paris: Le Seuil, 1985.

SANTOS, Maria da Graça. Os santuários como lugares de construção do sagrado e de memória hierofânica: esboço de uma tipologia. In: ROSENDAHL, Zeny; CORRÊA, Roberto. Geografia cultural: uma antologia. Rio de Janeiro: EDUERJ, 2013.v. 2.

SANTUÁRIO de Fátima. [S. I.], 2017. Página oficial do Santuário de Nossa Senhora do Rosário de Fátima. Disponível em: http://www.fatima.pt/pt/. Acesso em: 27 maio 2017.

SOUZA, Jorge Pedro. Teorias da notícia e do jornalismo. Chapecó: Argos, 2002.

DUCROT, Oswald; TODOROV, Tzvetan. 0 Dicionário enciclopédico das ciências da linguagem. São Paulo: Perspectiva, 2001.

VATICAN. A Santa Sé. [S. l.], 2017. Site oficial do Vaticano. Disponível em: http://w2.vatican.va/content/vatican/it.html. Acesso em: 27 de maio 2017

VATICAN. Cânones 1230 a 1234 do Código de Direito Canônico. 4. ed. Lisboa, 1983. Versão portuguesa. Conferência Episcopal Portuguesa. Disponível em: http://www.vatican.va/archive/cod-iuris-canonici/portuguese/codex-iuriscanonici po.pdf. Acesso em: 27 maio 2017.

\title{
Memory in the Sanctuary of Fatima: a discursive study on the narrative of apparitions
}

\author{
Abstract \\ This article aims to investigate the process of redecoration and \\ memory in the confluence between the fields of History and
}


Journalism. This research is based on a conceptual study on event, temporality and the methodology of discursive analysis. The case study analyzes reports published by Revista Sábado on the backstage of the Pope's visit to the Sanctuary of Fátima, in Portugal, in May 2017. The results of such survey reveal symbols, archives and conducts in the discursive events; the commemoration of centenary is the spectacle-event, whose temporality covers past, present and future; the space of the Sanctuary, where the ritual of redecoration takes place, preserves the symbol of the historical event - sacralization of repetition - and, as memory locus, the interweaving of temporalities; serving as the mortuary chamber of the past and as space of resurgence of the event in the future.

\section{Keywords}

Memory. Event. Temporality. Discourse.

Recebido em 07/02/2018

Aceito em 26/07/2018 